\title{
Mudanças socioambientais no uso da terra em Altamira, Amazônia oriental
}

\section{Environmental changes in land use in Altamira, Eastern Amazon}

Maristela Marques Silva - Mestre em Agroecossistemas - UFSC, Doutora em Ciências Agrárias - UFRA, docente da Universidade Federal do Pará/UFPA. E-mail: stela@ufpa.br

Francisco Assis Oliveira - Doutor em Hidrologia e Manejo de Ecossistemas. Instituto de Ciências Agrárias (ICA), Universidade Federal Rural da Amazônia (UFRA). E-mail: francisco.oliveira@ufra.edu.br

Antônio Cordeiro Santana - Doutor em Economia Rural, docente da Universidade Federal Rural da Amazônia (UFRA), Instituto Socioambiental e Recursos Hídricos (ISARH). E-mail: acsantana@superig.com.br

\section{Resumo}

Este estudo tem como objetivo analisar as principais mudanças no uso da terra e caracterizar os principais fatores que influenciam estas mudanças a partir de um estudo de caso no "Projeto de Assentamento Assurini", uma área representativa dos sistemas de produção agrícolas do município de Altamira, no Estado do Pará. Foram entrevistadas 50 famílias que residem no assentamento no período de outubro de 2012 a julho de 2013. As análises dos dados foram realizadas através da estatística multivariada, com análise fatorial e a análise de agrupamentos, utilizando 15 variáveis ligadas aos sistemas de produção. Os resultados indicaram que a criação de bovinos, o cultivo de cacau, aspectos ambientais, outras fontes de renda e as culturas anuais são os principais fatores que determinam as mudanças no uso da terra. Constatou-se, ainda, a diminuição das áreas de floresta primária, diminuição das áreas com cultivos anuais e o crescimento da dependência das famílias de outras fontes de renda.

\section{Palavras-chave}

Agricultura Familiar. Floresta Primária. Bovinos. Cacau. Culturas Anuais.

\begin{abstract}
This study aims to analyze the major changes in land use and characterize the main factors influencing these changes from a case study in "Settlement Project Assurini", a representative area of agricultural production systems in the municipality of Altamira, in the State of Pará. We interviewed 50 families living in the settlement from October 2012 to July 2013. Data analyzes were performed using the multivariate analysis, with factor analysis, and cluster analysis using 15 variables related to production systems. The results indicated that the cattle, cocoa farming, environmental, other sources of income and annual crops are the main factors that determine the changes in land use. It was found also decreased in the areas of primary forest, decrease in areas with annual crops and the growing dependence of the families of other sources of income.
\end{abstract}

\section{Keywords}

Family Farming. Primary Forest. Cattle. Cocoa. Annual Crops. 


\section{INTRODUÇÃO}

O uso da terra, em geral, tem sido considerado um problema ambiental local. No entanto, as ações humanas estão alterando o ambiente terrestre a taxas sem precedentes em todo o mundo, impulsionadas pelo avanço de cultivos agrícolas, pastagem e expansão das áreas urbanas, tornando-se um problema global à medida que tem habilitado os humanos a se apropriar dos recursos naturais do planeta, utilizados de forma não racional e causando impactos irreversíveis aos ecossistemas (FOLEY et al., 2005).

As mudanças no uso da terra são intensas em todo o mundo, mas, particularmente, na Amazônia brasileira, esse processo tem atraído atenção nos últimos trinta anos devido ao desmatamento acelerado, resultado de ocupação desordenada por meio de programas de desenvolvimento baseados em eixos de desenvolvimento, que resultaram na construção de estradas como a Rodovia Transamazônica (BATISTELLA; MORAN, 2005; BRONDIZIO, 2014). O município de Altamira, no estado do Pará, foi uma das áreas centrais do Programa Integrado de Colonização (PIC) e sofreu mudanças drásticas em sua estrutura produtiva, passando de uma região que tinha sua base econômica no extrativismo de produtos da floresta, para uma economia baseada em atividades agrícolas, direcionadas para o mercado.

As formas de uso da terra no município de Altamira acompanharam as etapas que ocorreram na região da Transamazônica como um todo. $\mathrm{Na}$ fase inicial de ocupação, que envolveu o período de 1972 a 1978, a base produtiva da região foram as culturas anuais (arroz, milho, feijão e mandioca), subsidiadas com crédito a juros baixos (CASTELLANET et al., 1998). As culturas perenes foram introduzidas na região a partir de 1976, destacando-se a pimenta-do-reino, que recebeu incentivos fiscais do Banco do Brasil, e o cacau, incentivado pelo Programa Procacau (SABLAYROLLES; ROCHA, 2003).

Essa etapa durou aproximadamente dez anos. No entanto, no final da década de 1980, ocorrem problemas fitossanitários, queda dos preços e dificuldades com a comercialização, causando o declínio das culturas perenes em toda a região da Transamazônica. Tal declínio favoreceu o desenvolvimento da pecuária na região, principalmente nos pequenos e médios estabelecimentos (TOURRAND et al., 1998). Durante o processo de ocupação, vários fatores têm influenciado as mudanças de uso da terra na região. Brondizio (2009) destaca que o efeito da idade da família, os efeitos periódicos como flutuações na migração, diferentes políticas de crédito, inflação, entre outras, são determinantes para tais mudanças. 
Atualmente, Altamira entra novamente no cenário nacional com a implantação de uma das principais obras de infraestrutura do Programa de Aceleração do Crescimento (PAC) com a construção do Complexo Hidrelétrico do Xingu, o que resultou em impactos ambientais, sociais e econômicos para a região como um todo (CORRÊEA, 2016). A partir deste contexto, este estudo tem como objetivo analisar as principais mudanças no uso da terra e caracterizar os principais fatores que influenciam estas mudanças em sistemas de produção familiares. Para entender essas mudanças foi realizado um estudo de caso no Projeto de Assentamento Assurini, uma área próxima à sede de Altamira, considerada um polo de produção agrícola e que possui relações econômicas, sociais e ambientais importantes para o município.

\section{MATERIAIS E MÉTODOS}

\section{1 ÁREA DE ESTUDO}

A área conhecida como Projeto de Assentamento Assurini localizase próxima à sede do município de Altamira. A primeira frente de ocupação da área começou na margem direita do rio Xingu, na época do Segundo Ciclo da Borracha, na década de 1940, com a migração de famílias nordestinas para explorar o látex da borracha, sendo intensificada na década de 1960, com o surgimento do extrativismo de pele de animais silvestres e coleta de castanha (PACHECO et al., 2009).

No final dos anos de 1970, tais famílias começaram a reivindicar, junto ao INCRA, a regularização fundiária e em 1981 foi iniciada a demarcação das primeiras áreas ocupadas pelas famílias (PACHECO et al., 2009).No entanto, a área só foi oficializada pelo INCRA em 1995, na categoria de Projeto de Assentamento (PA), devido às políticas de regularização das ocupações já existentes que haviam sido iniciadas em meados da década de 1990. O assentamento possui uma área de $32.140,15 \mathrm{~km}^{2}$ e conta com 574 domicílios ocupados e 1.453 habitantes (IBGE, 2010).

A pesquisa foi desenvolvida de outubro de 2012 a julho de 2013, sendo entrevistadas 50 famílias que residem em 04 localidades no Projeto de Assentamento Assurini. Estas localidades foram escolhidas por estarem bem distribuídas ao longo da área do assentamento e serem de fácil acesso, pois se localizam nas margens ou próximas da rodovia Transassurini (Figura 1). 
Figura 1 - Localização das propriedades no Projeto de Assentamento Assurini, Altamira - Pará

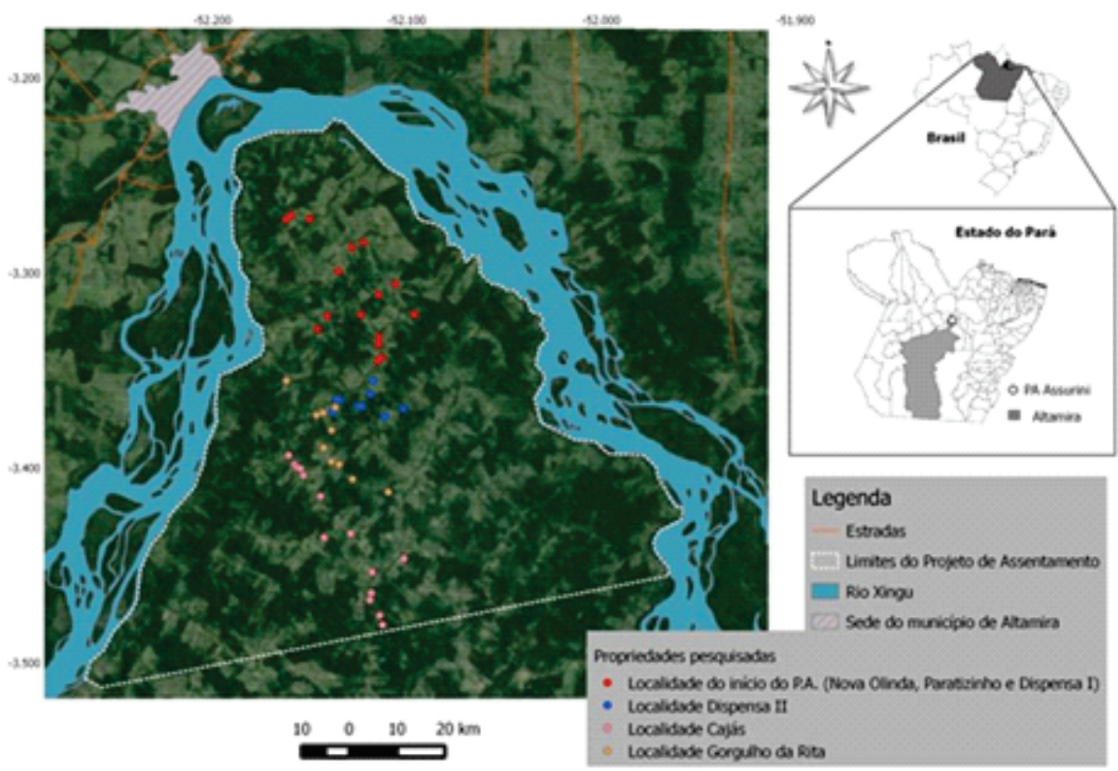

Fonte: Elaborado por M. J. M. PEREIRA

\subsection{COLETA E ANÁLISE DOS DADOS}

As informações foram obtidas por meio de entrevistas semiestruturadas onde foram abordados aspectos relacionados ao histórico de vida das famílias, caracterização dos sistemas de produção, mudanças nas práticas de manejo e principais formas de uso da terra no assentamento. Além das entrevistas, foram realizadas visitas nas parcelas cultivadas com o objetivo de conhecer as áreas e verificar o meio natural das propriedades estudadas.

Para entender as mudanças no uso da terra predominantes na área de estudo, utilizou-se da estatística multivariada com base na análise fatorial e na análise de agrupamentos. As informações foram obtidas por meio de questionários estruturados, o qual continha questões a respeito do sistema de produção, das formas de uso da terra, da renda das atividades, dos custos de produção e das limitações dos sistemas de produção desenvolvidos na região.

As variáveis que foram utilizadas na análise são as seguintes:

X1 - Tamanho da propriedade (TP) - ha

X2 - Área de floresta primária (AFP) - ha

X3- Área de floresta secundária (AFS) - ha 
$\mathrm{X} 4$ - Cabeças de bovinos $(\mathrm{CB})-\mathrm{n}^{\circ}$

X 5 - Mão-de-obra familiar (MOF)

X 6 - Renda do Gado (RG) - R\$

X 7 - Renda da cultura do cacau (RCC) - R\$

$\mathrm{X} 8$ - Rendas de culturas anuais e outras produções (ROP) - R \$

X 9 - Renda obtida com aposentadoria (RA) - R\$

X 10- Renda obtida com empregos (RE) - R\$

X 11-Custo manutenção da pastagem (CMP) - R \$

$\mathrm{X} 12$ - Custo com vacinas e sal mineral (CVS) - R\$

X13 - Custo na aquisição de insumo (CAI) - R\$

$\mathrm{X} 14$ - Custo com tratos culturais do cacau (CTC) - R\$

X15 - Custos com culturas anuais e outras produções (CCA) - R\$

A análise fatorial, de modo geral é utilizada para estudar a estrutura das interrelações entre um grande número de variáveis, definindo um conjunto de variáveis que são fortemente interrelacionadas, denominadas de fatores. Esses grupos de variáveis (fatores), que são altamente relacionados, são considerados como representantes das dimensões dentro dos dados (HAIR et al., 2009). Conforme Hair et al. (2009), um modelo de análise fatorial na forma matricial, é definido pela equação 1 :

$$
X=\alpha F+\varepsilon
$$

\section{Em que:}

$\mathrm{X}=$ é o $\mathrm{p}$-dimensional vetor transposto das variáveis observáveis, denotado por $\mathrm{X}=(\mathrm{x} 1, \mathrm{x} 2, \ldots, \mathrm{xp})^{\prime} ; \mathrm{F}=$ é o q-dimensional vetor transposto de variáveis não observáveis ou variáveis latentes chamadas de fatores comuns, denotado por, $\mathrm{F}=(\mathrm{f} 1, \mathrm{f} 2, \ldots, \mathrm{fq})$ ', sendo que $\mathrm{q}<\mathrm{p} ; \varepsilon=$ é o p-dimensional vetor transposto de variáveis aleatórias ou fatores únicos, $\varepsilon=(\mathrm{e} 1, \mathrm{e} 2, \ldots, \mathrm{ep})^{\prime} ; \alpha=$ é a matriz $(\mathrm{p}, \mathrm{q})$ de constantes desconhecidas, chamadas de cargas fatoriais. No modelo de análise fatorial pressupõe-se que os fatores específicos são ortogonais entre si e com todos os fatores comuns. Normalmente, $\mathrm{E}(\varepsilon)=\mathrm{E}(\mathrm{F})=0$ e $\operatorname{Cov}(\varepsilon, \mathrm{F})=0$.

Os fatores serão identificados por meio da técnica da raiz latente, que parte do princípio de que qualquer fator individual deve explicar a variância de pelo menos uma variável para que seja mantido para interpretação. Cada variável contribui com um valor 1 do autovalor total. Com efeito, apenas os fatores que têm raízes latentes ou autovalores maiores que 1 são considerados significantes e os demais fatores, com autovalores menores do que 1, são considerados insignificantes e descartados (SANTANA, 2007). 
Para facilitar a interpretação dos fatores é realizada uma rotação ortogonal pelo método Varimax, que procura minimizar o número de variáveis fortemente relacionadas com cada fator, permitindo obter fatores mais facilmente interpretáveis. Para identificar a adequação do método à amostra de dados, foi utilizado o teste de Kaiser-Meyer-Olkin Measure of Sampling Adequacy (KMO), que se baseia no princípio de que a inversa da matriz de correlação se aproxima da matriz diagonal, comparando as correlações entre as variáveis observadas. Os valores do teste variam de 0 a 1 e os valores de KMO abaixo de 0,50 indicam a não adequabilidade da análise. Foi também aplicado o teste esferecidade de Barllet, que fornece a significância estatística de que a matriz de correlação tem correlações significantes com pelo menos uma das variáveis (HAIR et al., 2009).

Para entender como os principais fatores identificados na análise fatorial fazem parte do modo de vida das 50 famílias, realizou-se a análise de agrupamentos por meio do método hierárquico, com as mesmas variáveis usadas na análise fatorial. Todas as análises estatísticas foram realizadas utilizando o Programa Estatístico Statistical Package for Social Science (SPSS), versão 20.

\section{RESULTADO E DISCUSSÃO}

\subsection{CARACTERIZANDO O USO DA TERRA NO ASSENTAMENTO}

Entre as famílias que participaram deste estudo, os homens possuem idade no intervalo de 29 \pm 79 anos, com média de 55 anos, e as mulheres, idades de $26 \pm 74$ anos, com média de 50 anos. O número de filhos por família varia de $1 \pm 11$ filhos, com o número médio de 4,7. No entanto, nota-se uma grande mobilidade de jovens e adultos na área do assentamento, já que apenas 27\% dos filhos moram com a família na área; 44\% moram em Altamira; 19\% moram na área do assentamento, mas em outras propriedades; e 10\% moram em outras cidades.

Por estar localizada muito próxima à sede do município, na área do assentamento ocorre uma grande mobilidade de pessoas, que se intensificou a partir da construção do Complexo Hidrelétrico de Belo Monte, em Altamira. Assim, 14\% (n.7) das famílias informaram que os filhos saíram recentemente do assentamento para trabalhar em empresas prestadoras de serviços ou no consórcio construtor da obra em Altamira. 
As primeiras famílias que chegaram ao assentamento na década de 1970, dedicaram-se exclusivamente ao plantio das culturas anuais por meio do sistema de corte e queima, com destaque para o cultivo de mandioca (Manihot esculenta Crantz) para produção de farinha, que era o principal meio de subsistência dessas famílias. Com a venda da farinha, as famílias conseguiram recursos para continuar investindo em outros cultivos como o arroz (Oriza sativa L.), o milho (Zea mays L.) e o caupi (Vigna unguiculata (L.) Walp).

A partir de 1990 inicia-se o processo de organização da comunidade em torno de reivindicações a respeito da melhoria da infraestrutura do assentamento, como a abertura da estrada e a construção de escolas, culminando com o processo de regularização do assentamento realizado pelo Instituto Nacional de Colonização e Reforma Agrária (INCRA), em 1995. Logo em seguida, é realizada a abertura da rodovia Transassurini que percorre toda área do assentamento.

Essas mudanças no assentamento influenciaram diretamente as formas de uso da terra, resultando em um novo direcionamento nas atividades agrícolas, notadamente o surgimento dos primeiros plantios de pastagem, por meio da implantação dos primeiros financiamentos através do Fundo Constitucional de Desenvolvimento da Região Norte (FNO).

A partir do ano 2000 foram introduzidos os primeiros cultivos de cacau e de hortaliças. Essas atividades foram favorecidas pela abertura da estrada, o que facilitou o transporte dos produtos para serem comercializados na Feira do Produtor na sede do município. Neste período também foram introduzidos os primeiros Sistemas Agroflorestais (SAF), por intermédio de uma iniciativa do Projeto Roça Sem Queimar ${ }^{1}$, tendo o cacau o como espécie principal, geralmente associada com espécies florestais ou frutíferas de valor econômico na região.

No entanto, a partir da implantação da atividade pecuária, ocorrem mudanças significativas na estrutura produtiva do assentamento e os cultivos anuais começam a dar espaço para pastagem, resultando em mudanças nas áreas cultivadas no assentamento (Figura 2).

O Projeto Roça Sem Queimar foi uma iniciativa realizada pela Fundação Viver Produzir e Preservar, com o apoio do Ministério do Meio Ambiente, implantada na Região da Transamazônica a partir do ano 2000, que visava buscar alternativas de preparo de área sem o uso do fogo. 
Figura 2 - Demonstrativo da área média cultivada pelas famílias nos anos de 2000 e de 2013 no Projeto de Assentamento Assurini, em Altamira - Pará

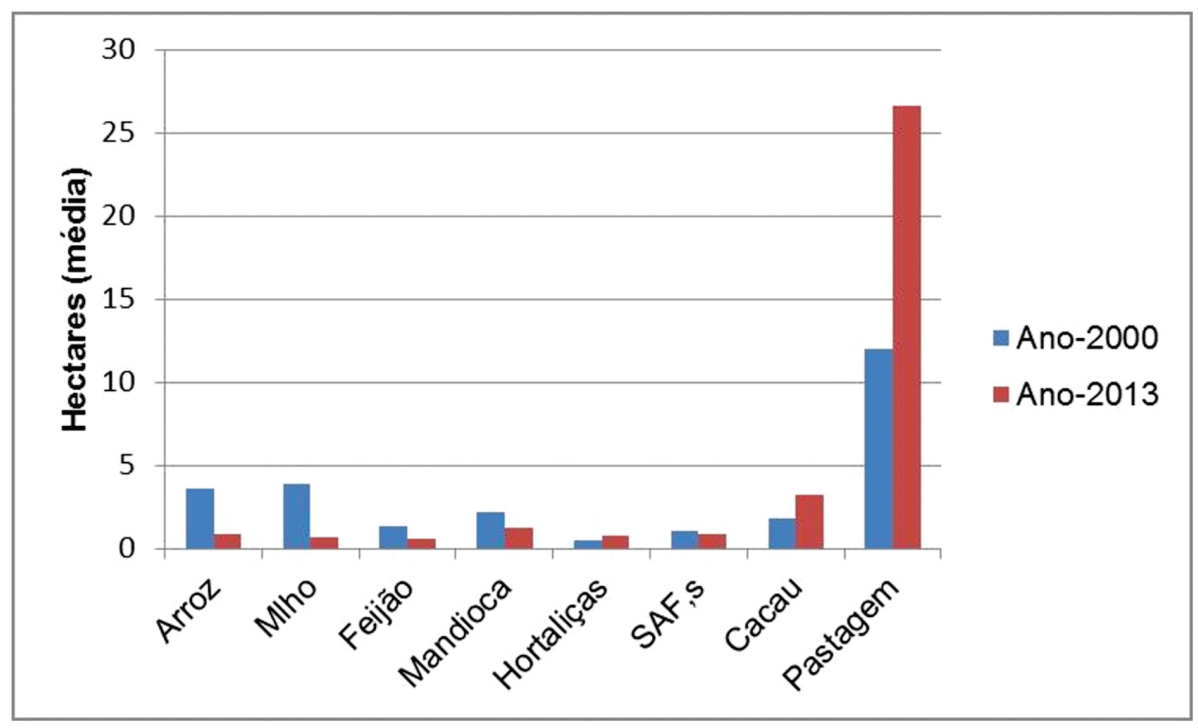

Fonte: Elaborado pelos autores

Como se nota, no período de treze anos houve uma redução nas áreas cultivadas com os cultivos anuais e uma expansão das áreas cultivadas com cacau e pastagem, indicando a expansão da pecuária na área do assentamento.

\subsection{FATORES QUE INFLUENCIARAM AS MUDANÇAS DE USO DA TERRA NO ASSENTAMENTO}

Para identificar os principais fatores que influenciam as formas atuais de uso da terra no assentamento foi utilizada a análise fatorial, a partir da organização das variáveis envolvidas no sistema de produção.

O resultado do teste KMO foi de 0,586; o do teste de Bartlett foi de 452.638, significante a 1\%; e o valor do Determinante foi de 3,75, demonstrando a adequação da amostra à análise fatorial. Esses resultados indicam que as variáveis são correlacionadas e que a solução do modelo é a mais adequada, portanto, a amostra de dados se adequa à aplicação do modelo de análise fatorial (SANTANA, 2007). Por intermédio do critério da raiz latente, foram definidos cinco fatores envolvidos no sistema de produção (Tabela 1). 


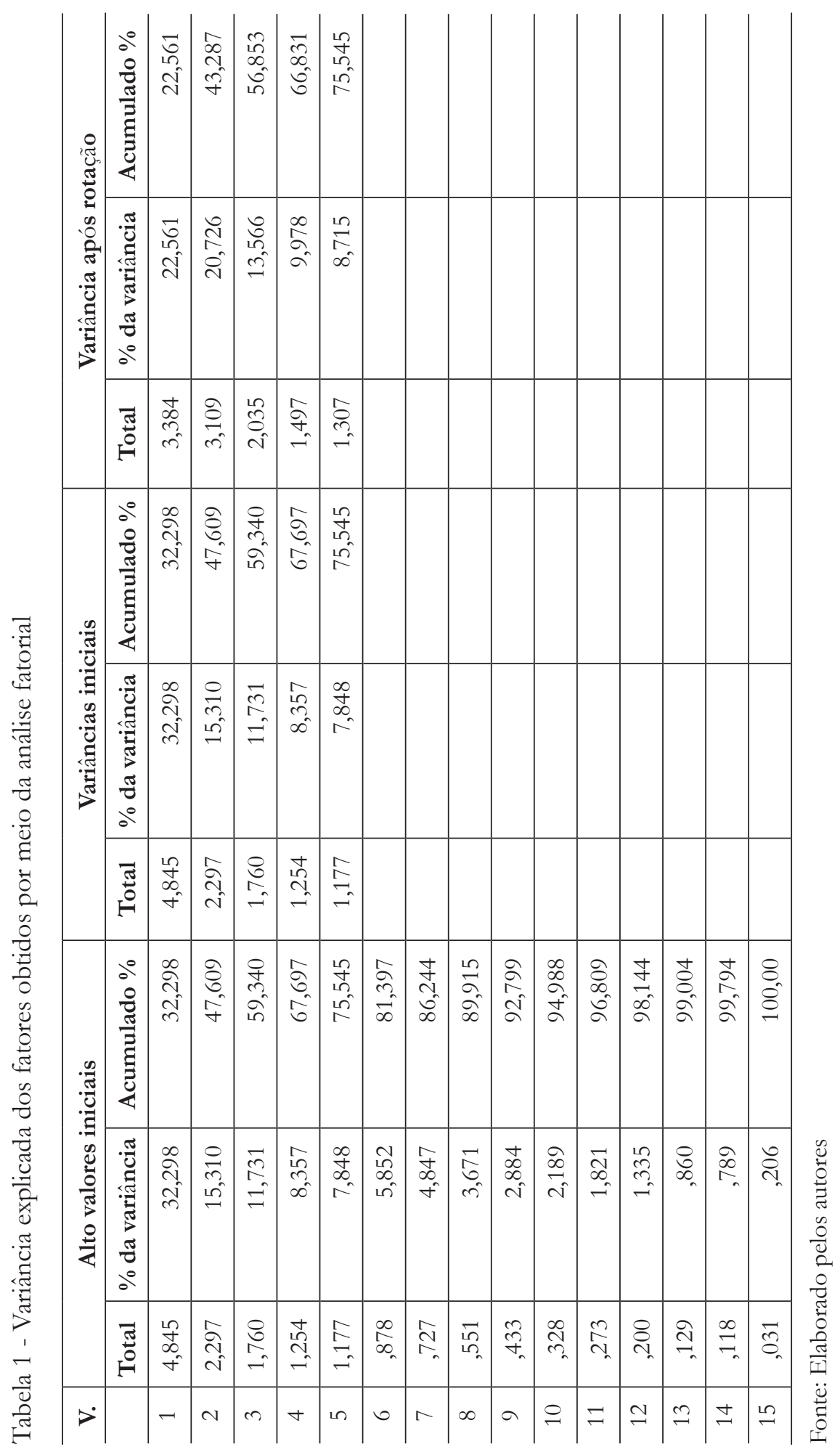


Os fatores identificados na análise explicam $75,54 \%$ da variância total, indicando uma boa representatividade da variância total dos dados. Foram identificadas, ainda, as variáveis que compõem cada fator e colocada a comunalidade correspondente a cada variável. A comunalidade representa a proporção da variância captada pelos fatores para cada indicador, ou seja, o poder de explicação destes fatores em relação a cada variável (Tabela 2). A escolha das variáveis que formam cada um dos fatores ocorreu verificando-se as cargas fatoriais de cada variável, da esquerda para direita e ao longo de cada linha, elegendo-se a carga fatorial de maior valor absoluto (SANTANA, 2007).

Tabela 2 - Matriz de cargas fatoriais rotacionadas

\begin{tabular}{|c|c|c|c|c|c|c|}
\hline \multirow{2}{*}{ Variáveis } & \multicolumn{5}{|c|}{ Fatores } & \multirow{2}{*}{$\begin{array}{l}\text { Comu- } \\
\text { nalidade }\end{array}$} \\
\hline & FPP & FPC & FAAM & FOR & FCAO & \\
\hline $\mathrm{N}^{\circ}$ de cabeças de bovinos (CB) & 827 & 140 & 222 & 167 &,- 088 & ,789 \\
\hline Mão-de-obra familiar (MOF) & ,722 &,- 119 &,- 1.15 &,- 159 & 114 & ,587 \\
\hline $\begin{array}{l}\text { Custo com manutenção da } \\
\text { pastagem }(\mathrm{CMP})-\mathrm{R} \$\end{array}$ & ,734 & ,414 & ,301 & 064 &,- 017 & ,805 \\
\hline $\begin{array}{l}\text { Custo com vacinas e sal mine- } \\
\text { ral (CVS) - R\$ }\end{array}$ & ,791 & ,414 & ,301 & 064 &,- 017 & ,743 \\
\hline Renda do gado (RG) - R\$ &, 588 & ,487 & ,194 & 207 &,- 184 & ,698 \\
\hline $\begin{array}{l}\text { Renda da cultura do cacau } \\
\text { (RCC) - R\$ }\end{array}$ & ,008 & ,917 & ,078 &, 047 &,- 004 &, 850 \\
\hline $\begin{array}{l}\text { Custo com tratos culturais do } \\
\text { cacau (CTC) - R\$ }\end{array}$ &,- 040 & ,912 & ,228 & 038 &,- 009 & ,888 \\
\hline Custo na aquisição de insumo & ,301 & ,768 & ,010 & 093 & 074 & ,694 \\
\hline $\begin{array}{l}\text { Área com floresta secundária } \\
\text { (AFS) - ha }\end{array}$ &,- 357 &,- 474 & ,245 & ,020 & ,280 & ,491 \\
\hline $\begin{array}{l}\text { Área de floresta primária } \\
(\mathrm{AFP})-\mathrm{ha}\end{array}$ & ,076 & ,097 & 900 &,- 154 &,- 067 & ,852 \\
\hline Área da propriedade (AP) - ha & ,374 &, 118 & 879 & ,062 &,- 049 & ,934 \\
\hline $\begin{array}{l}\text { Renda obtida com aposenta- } \\
\text { doria }(\mathrm{RA})-\mathrm{R} \$\end{array}$ & ,140 &,- 100 & ,045 & ,859 & ,117 & ,784 \\
\hline $\begin{array}{l}\text { Renda obtida com empregos } \\
\text { (RE) - R\$ }\end{array}$ & ,073 &,- 300 & , 166 &,- 782 & ,055 & ,738 \\
\hline
\end{tabular}

Fonte: Dados da pesquisa

Em relação às comunalidades obtidas, destacam-se as variáveis: área da propriedade $(0,934)$, custo com tratos culturais do cacau $(0,888)$, área de floresta primária $(0,852)$ e renda da cultura do cacau $(0,850)$, demonstrando que essas variáveis são significantes para determinação dos fatores. As variáveis área de 
floresta secundária $(0,491)$ e mão-de-obra familiar $(0,587)$ apresentaram valores baixos, indicando que essas variáveis tiveram uma menor contribuição na determinação dos fatores.

O primeiro fator, denominado de produção pecuária (FPP), explicou $31,439 \%$ da variância total, composto pelas seguintes variáveis: cabeças de bovinos (CB), mão-de-obra familiar (MOF), custo manutenção da pastagem (CMP), custo com vacinas e sal mineral (CVS) e renda do gado (RG).

O segundo fator, denominado produção de cacau (FPC), explicou 15,31\% da variância total dos dados, sendo formado pelas seguintes variáveis: renda da cultura do cacau (RCC), custo com tratos culturais do cacau (CTC), custo na aquisição de insumo (CAI) e área com floresta secundária (AFS)

O terceiro fator, denominado de aspecto ambiental (FAAM), explicou $11,73 \%$ da variância total dos dados, sendo formado pelas seguintes variáveis: área de floresta primária (ha) e área da propriedade (ha).

O quarto fator, denominado outras fontes de renda (FOFR), explicou $8,35 \%$ da variância total dos dados, sendo formado pelas variáveis: renda obtida com aposentadoria (RA) e renda obtida com empregos (RE).

O quinto fator, denominado produção de culturas anuais e outras produções (FCAO) explicou 7,848\% da variância total dos dados, formado pelas seguintes variáveis: custos com culturas anuais e outras produções (CCAOP), rendas de culturas anuais outras produções (ROP).

\subsection{GRUPOS DE FAMÍLIAS COM CARACTERÍSTICAS SIMILARES DE USO DA TERRA NO PROJETO DE ASSENTAMENTO ASSURINI}

O principal resultado da análise de agrupamento é a formação de grupos ou tipos, a partir dos valores obtidos na análise fatorial, com características similares. Foram formados cinco grupos, que se agruparama partir de características similares de uso da terra dentro do assentamento. Os grupos foram denominados a partir das variáveis mais marcantes que se delinearam em cada grupo e organizados em ordem a partir do número de famílias que compôs cada grupo. Para aprofundar e facilitar a caracterização de cada grupo, e destacar os pontos marcantes e as diferenças entre os grupos, foi organizada uma tabela que sintetiza as principais características de cada grupo (Tabela 3). 


\begin{tabular}{|c|c|c|c|c|c|}
\hline 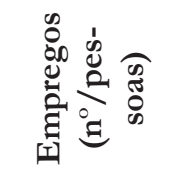 & in & 1 & in & $N$ & $r$ \\
\hline 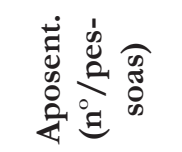 & $\forall$ & 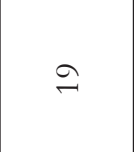 & 1 & $\stackrel{ }{\sim}$ & 1 \\
\hline ن & $\stackrel{0}{\rightarrow}$ & $\hat{o}_{1}$ & $\stackrel{n}{\sim}$ & $\rightarrow$ & $\overrightarrow{\mathrm{v}}$ \\
\hline 己ֶّ & $\stackrel{n}{m}$ & $\stackrel{\infty}{\mathrm{i}}$ & $\tilde{v}$ & 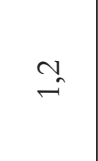 & $\frac{R}{2}$ \\
\hline 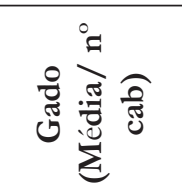 & $\stackrel{\circ}{\sim}$ & 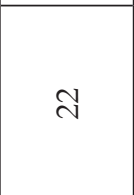 & in & in & $\bullet$ \\
\hline 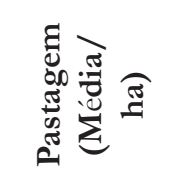 & $\stackrel{\sim}{f}$ & $\hat{N}$ & $\stackrel{+}{\sim}$ & $\stackrel{0}{\sim}$ & $\infty$ \\
\hline 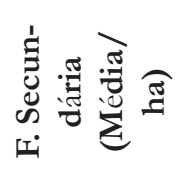 & $\sim$ & $a$ & $\infty$ & $a$ & $r$ \\
\hline 茎 & $\vec{m}$ & in & ले & $\widetilde{\curvearrowright}$ & ৩ \\
\hline 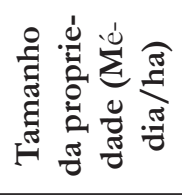 & $\grave{\infty}$ & 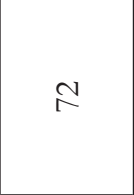 & $\stackrel{\infty}{\sim}$ & N & $\stackrel{\infty}{+}$ \\
\hline$\stackrel{0}{0}_{0}^{0}$ & 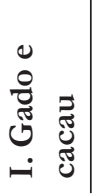 & 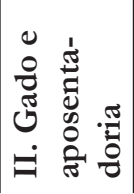 & 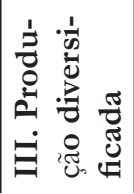 & 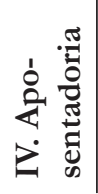 & 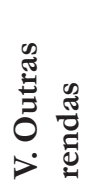 \\
\hline
\end{tabular}


Os cinco grupos serão descritos com suas principais características produtivas a seguir:

\section{Grupo 1 - Famílias com criação de bovinos e cacau}

Esse grupo é formado por $24 \%$ das famílias (n.12) entre as quais predomina a criação de bovinos como a atividade principal e cuja outra atividade importante é o cultivo de cacau. Em relação às culturas anuais, neste grupo apenas cinco famílias haviam plantado a cultura do milho em 2013 e oito famílias estavam cultivando a mandioca na época da realização da pesquisa.

\section{Grupo 2 - Famílias com criação de bovinos e aposentadoria}

Esse grupo é formado por $20 \%$ das famílias (n.10), sendo que em nove famílias dois membros da família já estão aposentados. Além da aposentadoria, as outras fontes de renda são a criação de bovinos e pequenas áreas com cultivo de cacau. Neste grupo, as áreas de cultivo são reduzidas e na maior parte dos casos apenas o casal reside no lote, pois os filhos moram em outros locais no assentamento ou em Altamira.

\section{Grupo 3 - Famílias com produção diversificada}

Este grupo, formado por $20 \%$ das famílias estudadas (n.10), possui áreas com a cultura do cacau, cultivos anuais, produção de hortaliças, fruticultura em pequena escala e a criação de bovinos.

Entre os cultivos anuais, destacam-se a cultura da mandioca para venda in natura em supermercados e feiras livres de Altamira. As culturas do milho e do feijão também são verificadas em áreas menores do que um hectare e são destinadas principalmente ao consumo da família. Destacam-se seis famílias que trabalham na produção de hortaliças e algumas espécies frutíferas, as quais comercializam diretamente na Feira do Produtor em Altamira.

\section{Grupo 4 - Famílias de aposentados com pouca produção agrícola}

Esse grupo é formado por 18\% das famílias (n.9). Nele, a principal fonte de renda é a aposentadoria. As áreas de cultivo são pequenas e destinadas ao consumo da família e as áreas de pastagens encontram-se em processo de degradação, com uma média de cinco cabeças de gado por propriedade.

\section{Grupo 5 - Famílias dependentes de outras rendas}

Esse grupo é formado por $14 \%$ das famílias (n.7). Aqui, a principal renda vem de atividades desenvolvidas fora do sistema de produção. Neste grupo, 
um dos membros da família possui outra fonte de renda, fora da agricultura. Consequentemente, as áreas destinadas à produção agrícola e a criação de gado são reduzidas.

\subsection{CARACTERIZAÇÃO DOS PRINCIPAIS FATORES IDENTIFICADOS NA ANÁLISE FATORIAL}

\section{a) Fator - Produção Pecuária}

As variáveis ligadas à produção pecuária explicaram $31,43 \%$ da variância dos dados. A importância da atividade para a sustentabilidade econômica das famílias é bastante diferenciada, pois existem famílias que possuem apenas cinco hectares com pastagens, com $4 \pm 5$ cabeças de bovinos, assim como existem famílias que possuem mais de 70 hectares com pastagem e 150 cabeças de bovinos. Apesar dessa variação, a análise fatorial comprovou a importância dessa atividade nos cinco grupos definidos na análise de agrupamentos.

Em todos os grupos delineados na análise de agrupamento, a criação de bovinos está presente. Nos grupos I, II e III (Tabela 3), a criação de bovinos tem uma maior participação na renda das famílias, já nos grupos IV e V, a atividade faz parte do sistema de produção, mas as principais fontes de renda vêm de outras atividades.

A presença da criação de bovinos em todos os grupos está relacionada ao acesso ao crédito, pois $96 \%$ (n.46) das famílias que participaram deste estudo tiveram acesso a algum tipo de crédito, com destaque para o Fundo Constitucional de Desenvolvimento da Região Norte (FNO), que financiou 56\% (n.28) das famílias; seguido pelo Programa de Crédito Especial para Reforma Agrária (PROCERA), com 14\% (n.7); e pelo Programa Nacional da Agricultura Familiar (PRONAF-A), que financiou 12\% (n.6) das famílias.

Acrescente-se que Poccard-Chapuis (2003) afirma que a tendência de expansão da pecuária na região da Transamazônica estaria ligada à emergência de mercados consumidores locais, que sustentariam o preço e garantiriam o acesso ao mercado dos produtos da pecuária, destacando que em outros locais da Amazônia o consumo local é pequeno, uma vez que a maior parte da produção é comercializada para outros estados.

A expansão da pecuária na região teve como consequência direta uma pressão maior sobre o ambiente, refletida pela diminuição da área de florestas primárias dentro das propriedades. Segundo Brondizio et al. (2002), houve um aumento do desmatamento na região da Transamazônica, em 1996, associado à baixa inflação e ao retorno aos incentivos de crédito como o FNO. Esse fator é 
agravado pela baixa capacidade de suporte das pastagens na região, assim como o baixo nível tecnológico dos sistemas de produção desenvolvidos na região da Transamazônica (TONI, 2003).

Uma série de estudos vêm apontando para os impactos diferenciados de práticas agrícolas nos desmatamentos na região da Transamazônica, associado às atividades ligadas à criação de bovinos um impacto maior no desmatamento do que cultivos comerciais ou de subsistência e a expansão do desmatamento em áreas de assentamento (BRONDIZIO et al., 2002; BRONDIZIO, 2009; GODAR et al; 2012; MORAN; BRONDIZIO: BATISTELLA, 2008; ALENCAR et al., 2016).

\section{b) Fator - Produção de Cacau}

As variáveis relacionadas ao sistema de produção do cacau explicaram $15,31 \%$ da variância dos dados. Apesar de o cultivo ser desenvolvido em pequena escala, em todos os grupos definidos na análise de agrupamentos existem áreas cultivadas com cacau. Atualmente, 68\% das famílias (n.34) que participam deste estudo estão cultivando a cultura do cacau, com cultivos que variam de $0,5 \pm 15$ hectares, com uma média de 3,20 hectares cultivados.

As áreas cultivadas com cacau no assentamento são pequenas quando comparadas com a área média cultivada nos municípios da região da Transamazônica, que é de 15 hectares (MENDES, 2000). Entretanto, representam o esforço das famílias em buscar cultivos que tenham um melhor acesso aos mercados locais e regionais e que tragam menos impactos ambientais.

\section{c) Fator - Os aspectos ambientais}

As variáveis relacionadas aos aspectos ambientais explicaram 11,73\% da variação dos dados e são compostas por: área da propriedade e área de floresta primária. No momento de ocupação do assentamento, as famílias demarcavam áreas em torno de $50 \pm 80$ hectares. No entanto, atualmente as áreas são bastante diversificadas, pois muitas famílias venderam o direito de posse, assim, o tamanho das propriedades estudadas varia de $10 \pm 165$ hectares, com uma média de 70,8 hectares.

As áreas de florestas primárias possuem tamanhos que variam de $10 \pm 72$ hectares, com uma média de 30,76 hectares. A quantidade de floresta primária que ainda existe na área de estudo está condicionada pelas estratégias de uso da terra e as opções tecnológicas nos sistemas de produção. Em relação às áreas de floresta secundária, 86\% (n.43) das famílias possuem florestas secundárias com dimensões de $1 \pm 32$ hectares, com um estoque médio de 7,7 hectares por propriedade. 
No momento de ocupação do assentamento, os agricultores implantaram suas roças ou pastagens sem levar em conta o que estava previsto no Código Florestal $^{2}$ para ser deixado como Reserva Legal e, atualmente, a maioria das famílias desmataram áreas a que tinham direito para implantar suas roças. Nos grupos I e II, as famílias já utilizaram as áreas de floresta primária previstas no Código Florestal e as florestas remanescentes nas propriedades fazem parte da Reserva Legal (Figura 3).

Figura 3 - Comparação entre áreas da propriedade, floresta primária, secundária e áreas cultivadas nos cinco grupos identificados no Projeto de Assentamento Assurini, Altamira - Pará

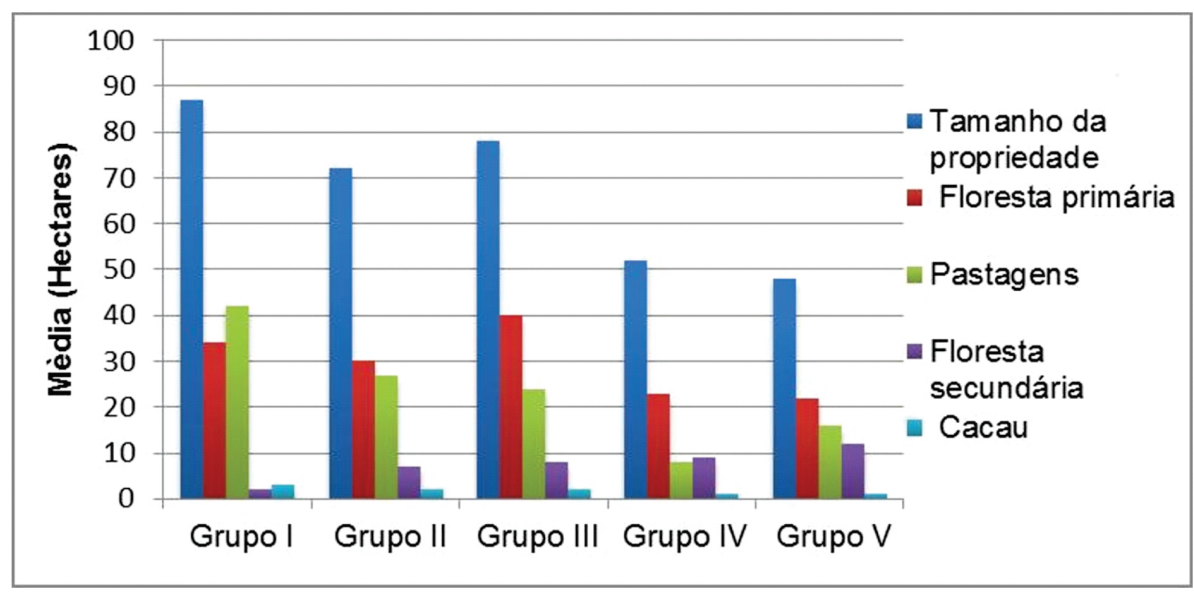

Fonte: Elaborado pelos autores

Nos demais grupos a relação está mais balanceada, com destaque para o grupo III, que é formado pelos agricultores diversificados, que possuem uma área de floresta primária maior. Ressalta-se que a diminuição das áreas de floresta primária foi citada por $60 \%$ das famílias como uma das principais limitações que impedem a continuidade dos cultivos anuais com a mesma frequência que se faziam nos primeiros anos de ocupação do assentamento.

d) Fator - Outras Fontes Renda

As variáveis relacionadas a outras fontes de renda explicaram 8,35\% da variância dos dados e estão compostas pelas variáveis: outras fontes de renda,

2 Segundo o código Florestal de 1965, Lei 4.771, vigente no momento de ocupação do assentamento, as áreas de reserva legal seriam de 50\% do imóvel rural. O novo Código Florestal, Lei $\mathrm{n}^{\circ}$ 12.651/2012,estabelece, no artigo III, que a Reserva Legal é de 80\% do imóvel rural. No entanto, no Estado do Pará, a Lei Estadual No 7.243, de 9 de janeiro de 2009, institui o Zoneamento Econômico Ecológico das áreas de influencia da BR-163 e Rodovia Transamazônica, que regulamentou em áreas consolidadas a reserva legal de 50\% do imóvel rural. 
recursos da aposentadoria, bolsa família e outros empregos. Entre as famílias que participam deste estudo, 46\% (n.23) obtêm renda da aposentadoria. Basicamente, a aposentadoria é a principal fonte de renda para os grupos II e IV, com a diferença de que, no grupo II, as famílias possuem também a renda da criação de bovinos, enquanto no grupo IV a aposentadoria é a principal renda da família (Figura 4).

Figura 4 - Outras fontes de renda e aposentadoria nos cinco grupos identificados no Projeto de Assentamento Assurini, Altamira- Pará

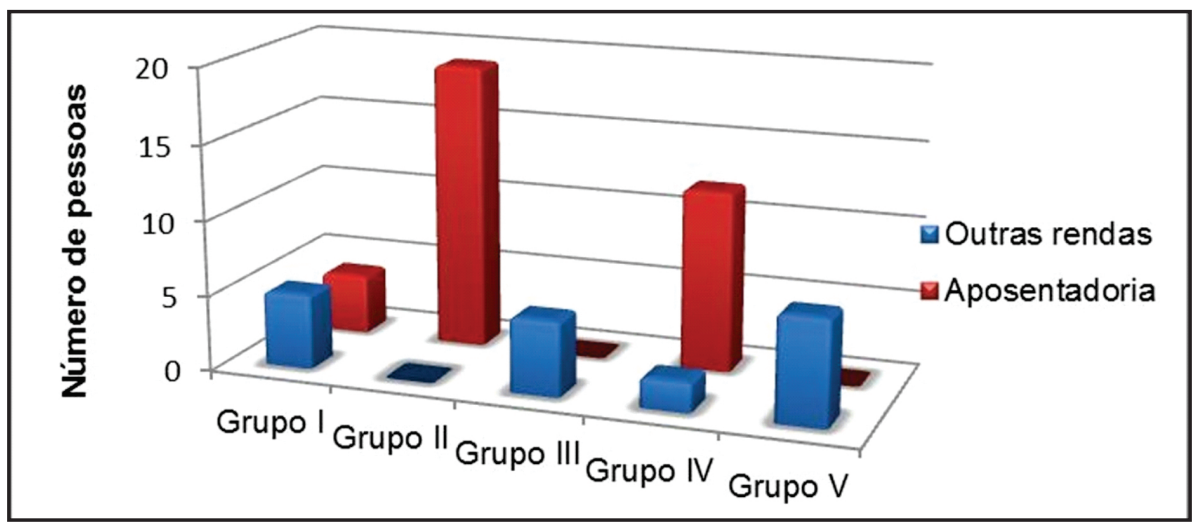

Fonte: Elaborado pelos autores

Em relação às outras fontes de renda, 44\% (n.22) das famílias desenvolvem algum tipo de atividade remunerada fora da agricultura e $22 \%$ (n.11) recebem auxílio do programa Bolsa Família. A importância das atividades não agrícolas foi comprovada por meio da análise de agrupamentos, demonstrando que, em quatro grupos I, III, IV e V, pelo menos um dos membros da família realiza atividades não agrícolas (Figura 4). Esse crescimento das atividades não agrícolas demonstra as limitações que a agricultura tem enfrentado na região como um todo.

Esta realidade é um fenômeno que vem ocorrendo no âmbito de unidades familiares de outras regiões do Brasil e vem sendo denominada pelos cientistas sociais de pluriatividade agrícola. Schneider et al. (2006) definem pluriatividade como um fenômeno que se caracteriza pela combinação das múltiplas inserções ocupacionais das pessoas que pertencem à mesma família, ocorrendo em situações em que os membros que compõem as famílias domiciliadas nos espaços rurais combinam atividades agrícolas com outras formas de ocupação, em atividades não agrícolas.

As atividades não agrícolas mencionadas pelas famílias são bastante variadas, mas as principais estão ligadas a empregos ofertados pela Secretaria Municipal de Educação, como por exemplo: professor, vigilante, merendeira e serviços gerais. 
Existem também agentes de saúde e outros profissionais liberais. A participação do poder municipal e federal, com a prestação de serviços básicos, contribuiu para que surgissem oportunidades de empregos no próprio assentamento.

\section{e) Fator - Produção de culturas anuais e outras produções}

Este fator impactou em 7,84\% na variância dos dados, sendo composto pelas variáveis relacionadas à renda e aos custos com as culturas anuais e outras produções. Na variável outras produções foram agregadas atividades como a produção de hortaliças e venda de outros produtos, como frutas originadas dos sistemas agroflorestais e galinha caipira, que são produzidos em pequenas proporções.

As culturas anuais são cultivadas por 50\% (n.25) das famílias que participaram deste estudo, com uma área média por família de 1,03 hectares. As famílias, em sua maioria, informaram que praticamente não cultivam mais arroz devido aos custos com mão de obra e por não terem mais área de floresta primária disponível para plantar, sendo priorizados os cultivos de milho e da mandioca, que obtém bons resultados quando plantados em áreas de floresta secundária.

Os cultivos anuais revelam retração quando comparados com a fase inicial de ocupação. Entretanto, ainda persistem no assentamento. A persistência dos cultivos anuais na região da Transamazônica já foi identificada em vários estudos realizados. Walker et al. (1998) e Homma (1998), na década de 1990, indicaram a importância das culturas anuais nos sistemas de produção para a subsistência das famílias. Em estudo mais recente, em três municípios da região, Rocha e Almeida (2013) constataram que grande parte das famílias não cultivam mais arroz, mas a maioria ainda realiza cultivos de feijão, milho e mandioca, confirmando a importância dessas culturas para os sistemas de produção da região.

Em nosso estudo, a falta mão-de-obra familiar foi identificada como fator limitante, pois a maioria dos filhos não mora com a família. Outro fator mencionado foi a idade média dos chefes de família, que passa de cinquenta anos. Em outros estudos, aspectos relativos à mão-de-obra e à composição familiar já haviam sido identificados como propulsores de mudanças em relação ao uso da terra na região da Transamazônica (BRONDIZIO, 2009; ROCHA, 2016). Essas limitações têm sido uma barreira para manutenção dos cultivos anuais no assentamento, pois essa atividade demanda mão-de-obra significativa para realizar o manejo, que envolve desde o preparo de área até a colheita.

Outra questão que tem limitado a expansão das áreas de cultivos está ligada ao acesso das famílias a serviços como assistência técnica e outras políticas públicas. Desde a ocupação do assentamento, a assistência técnica foi 
ocorrendo de forma pontual, por meio da atuação da Empresa de Assistência Técnica e Extensão Rural (EMATER), com ações direcionadas para programas específicos como a implantação de projetos de crédito como FNO, PROCERA e PRONAF-A. Além da concessão de crédito, apenas 30\% das famílias que participaram deste estudo receberam assistência em outras atividades como a produção de hortaliças e o cultivo do cacau.

\section{CONSIDERAÇÕES FINAIS}

As mudanças no uso da terra que se delinearam no assentamento foram moldadas a partir de um conjunto de fatores, que envolvem desde suas experiências com atividades agrícolas, até aspectos exógenos, ligados àspolíticas públicas e a conjuntura regional. A análise fatorial identificou a ampliação efetiva da criação de bovino e do cultivo do cacau ea diminuição das áreas com cultivos anuais, alémdo crescimento da dependência das famílias de outras fontes de renda, como a aposentadoria e os empregos no assentamento.

Apesar das limitações relacionadas aos aspectos produtivos e ambientais, a produção agrícola em pequenas proporções está presente em todos os grupos, demonstrando que existe potencial para ampliar e diversificar a produção, com a expansão dos cultivos de hortaliças e da produção de frutíferas. No entanto, a baixa produtividade dos cultivos e a falta de opções de renda podem levar as famílias a venderem os seus lotes e a se mudarem para a sede do município, resultando em uma concentração de terras na área do assentamento.

\section{AGRADECIMENTOS}

Às famílias do Projeto de Assentamento Assurini que participaram desta pesquisa, compartilhando informações a respeito de suas vivências e desafios nas várias etapas de ocupação do assentamento. À Fundação Amazônia de Amparo a Estudos de Pesquisa no Estado do Pará (FAPESPA), pela bolsa de doutorado que possibilitou a realização da pesquisa.

\section{REFERÊNCIAS}

ALENCAR, A.; PEREIRA, C.; CASTRO, I.; CARDOSO, A. SOUZA, L.; COSTA, R.; BENTES, A. J.; STELlA, O.; AZEVEDO, A.; GOMES, J.; NOVAES, R. Desmatamento nos Assentamentos da Amazônia: histórico, tendências e oportunidades. Brasília: IPAM, 2016. 93p. 
BATISTELA, M.; MORAN, E. F. Dimensões humanas do uso e cobertura das terras na Amazônia: uma contribuição do LBA. Acta Amazônica, Manaus, n. 35, v. 2, p. 249-257, 2005.

BRONDIZIO, E. S. Análise inter-regional de mudança do uso da terra na Amazônia. In: MORAN, E. F.; OSTROM, E. (Org.). Ecossistemas Florestais: interação homem-ambiente. São Paulo: EDUSP, 2009. p. 289-326.

BRONDIZIO, E. S.; MCCRCKEN, S. D.; MORAN, E. F.; SIQUEIRA, A. D.; NELSON, D.R.; RODRIGUES-PEDRAZA, C. The colonist footprint: towards a conceptual framework of deforestation trajectories among small farmers in frontier Amazônia. In: WOOD, C.; PORRO, R. (Ed.). Land use and deforestation in the Amazon. Gainesville, Fl, USA: University Press of Florida, 2002. p.133-160.

BRONDIZIO, E. S. Abordagens teóricas e metodológicas para o estudo de mudanças no uso da terra. In: VIEIRA, I. C.; TOLEDO, P. M.; SANTOS JUNIOR, R. A. O. Ambiente e Sociedade na Amazônia: uma abordagem interdisciplinar. Rio de Janeiro: Garamond. 2014. p. 149-178.

CASTELlANET, C.; SIMÕES, A.; CELESTINO FILHO, P. Diagnóstico preliminar da agricultura familiar na Transamazônica: indicações para pesquisa e desenvolvimento. Belém: EMBRAPA. Documentos 105. 1998. 48p.

CORRÊA, S.R. M. Neodesenvolvimento e conflitos sociais: o caso da hidrelétrica de Belo Monte. Novos Cadernos NAEA, Belém, v. 19, n. 3, p. 233-254, 2016.

FOLEY, J. A.; DEFRIES, R.; ASNER, G. P.; BARORD, C.; BONAN, G.; CARPENTER, S. R.; CHAPIN, F. S.; COE, M. T.; DALY, G. C.; GIBBS, H. K.; HELKOWSKI, J. H.; HOLLOWAY, T.; HOWARD, E. A.; KUCHARIK, C. J.; MONFREDA, C.; PATZ, J. A.; PRENTICE, I. C.; RAMANKUTTY, N.; SNYDER, P. K. Global consequences of land use. Sience, v. 309, n. 5735, p. 570-574, 2005.

GODAR, J.; TIZADO, E. J.; POKORNY, B.; JOHNSON, J. Tipology and characterization of amazon colonist: a case study along the Transamazon Highway. Human Ecology, n. 40, p. 251-267, 2012.

HAIR, J. R.; ANDERSON, R. E.; TATHAM, R.L.; BLACK, W.C. Análisemultivariada de dados. 6. ed. Porto Alegre: BOOKMAM, 2009. 688 p. HOMMA, A. K. Redução dos desmatamentos na Amazônia: política agrícola ou ambiental. In: HOMMA, A.K. O. (Org.). Amazônia: meio ambiente e desenvolvimento agrícola. Belém: EMBRAPA-CPATU, 1998. p. 119-143. 
IBGE - Instituto Brasileiro de Geografia e Estatística. Censo 2010. Disponível em: <http://www.ibge.gov.br/cidadesat/topwindow.htm>. Acesso em: 14 abr. 2014.

Censo Agropecuário. 2006. Disponível em: <http://www.ibge.gov. br/cidadesat/topwindow. htm>. Acesso em: 14 jun. 2012.

INPE - Instituto Nacional de Pesquisas Espaciais. Monitoramento da Floresta Amazônica por satélite. No período de 1997 a 2010. 2013. Disponível em: <http://www.inpe.br/prodes/>. Acesso em: 2013-03-29.

INPE - Instituto Nacional de Pesquisas Espaciais; Embrapa - Empresa Brasileira de Pesquisa Agropecuária. Levantamento de informações de uso e cobertura da terra na Amazônia. Sumário Executivo. 2011.

MENDES, F. A Cacauicultura na Amazônia Brasileira: potencialidades abrangência e oportunidades de negócios. Movendo Idéias, Belém, v. 5, n. 8, p. 53-61, 2000.

MORAN, E. F.; BRONDIZIO, E. S.; BATISTELLA, M. Trajetórias de desmatamento e uso da terra na Amazônia Brasileira: uma análise multiescalar. In: BATISTEllA, M.; MORAN, Emílio. F; ALVES, Diógenes. S. (Org.) Amazônia: natureza e sociedade em transformação. São Paulo: EDUSP, 2008, p. $137-180$.

PACHECO, P.; NUNES, W. ; ROCHA, C.; VIEIRA, I.; HERRERA, J. A.; SANTOS, K.; SILVA, T.; CAYRES, G.. Acesso a terra e meio de vida: examinando suas interações em três locais no Estado do Pará. Belém: CIFOR, 2009. 74 p.

PARÁ. Lei Estadual nº 7243, de 9 de janeiro de 2009. Dispõe sobre o Zoneamento Ecológico- Econômico da área de influência das Rodovias BR-163 (SantarémCuiabá) e BR-230 (Transamazônica) no Estado do Pará - Zona Oeste. Diário Oficial do Estado do Pará, Belém, 20 jan. 2009. Disponível em: <http:// www.mma.gov.br/port/conama/processos/606CC34C/Lei_7.243_ZEEBR163_09jan09.pdf.>. Acesso em: 5 dez. 2014.

POCCARD-CHAPUIS, R. Seguindo o caminho do gado numa estrada de colonização: cadeias produtivas bovinas e viabilidade de agricultura familiar na Transamazônica. In: TOURRAND, J. F.; VEIGA, Jonas. B. Viabilidade de sistemas agropecuários na agricultura familiar na Amazônia. Belém: EMBRAPA-CPATU, 2003. p. 325-353. 
ROCHA, C. G. S.; ALMEIDA, J. Lógicas de reprodução social, trajetórias produtivas e gestão do meio natural de agricultores familiares no Sudoeste do Pará, Brasil. Novos Cadernos NAEA, Belém, v. 16, n. 1, p. 149-172, 2013.

ROCHA, C. G. S. Reprodução social e práticas socioprodutivas de agricultores familiares do Pará. Jundiaí-SP: Ed. Paco, 2016. 257 p.

SABLAYROLLES, P.; ROCHA, C. G. Desenvolvimento sustentável da agricultura familiar na Transamazônica. Belém: AFATRA, 2003. 300 p.

SANTANA, A.C. Índice de desempenho competitivo das empresas de polpas de frutas no Estado do Pará. Revista de Economia e Sociologia Rural. Rio de Janeiro: v. 45. n. 3, p. 749- 775. 2007. Disponível em: <www.scielo.br/pdf/resr/ v45n3/a09v45n3.pdf>. Acesso em: 29 maio 2011.

SCHNEIDER, S.; CONTERATO, M. A.; KOPPE, L. R.; SILVA, C. C. Pluriatividade e as condições de vida dos agricultores familiares do Rio Grande do Sul. In: SCHNEIDER, S. (Org.) Diversidade da agricultura familiar. Porto Alegre: Editora da UFRGS, 2006. p. 137-165.

TONI, Fabiano. A conquista do FNO-especial pelos agricultores da Transamazônica e seus efeitos sobre a pecuarização da agricultura familiar. In: TOURRAND, J. F.; VEIGA, J. B. (Org.) Viabilidade de sistemas agropecuários na agricultura familiar na Amazônia. Belém: EMBRAPA-CPATU, 2003. p. 413-425.

TOURRAND, J. François; V., J. B.; QUANZ, D.; FERREIRA, L.A.; SIMÃO NETO, M. Produção Leiteira em área de Fronteira Agrícola da Amazônia: o caso do município de Uruará-Pará. In: HOMMA, A.K. O. (Org.) Amazônia: meio ambiente e desenvolvimento agrícola. Belém: EMBRAPA-CPATU, 1998. p. 346-365.

WALKER, R. T.; HOMMA, A.K.; SCATENA, F. N.; NEVES, A. C. P.; SANTOS, A. I. M.; CONTO, A., J.; PEDRAZA, C. D. R.; FERREIRA, C. A. P.; OLIVEIRA, Pedro, M.; CARVALHO, R. A. A evolução da cobertura do solo nas áreas de pequenos produtores na Transamazônica. In: HOMMA, A. K. O. (Org.) Amazônia: meio ambiente e desenvolvimento agrícola. Belém: EMBRAPACPATU, 1998. p. 321- 343. 